\title{
Acquisition of cocaine self-administration in male Sprague- Dawley rats: Effects of cocaine dose but not initial locomotor response to cocaine
}

\author{
Bruce H. Mandt ${ }^{1}$, Nickie L. Johnston ${ }^{1}$, Nancy R. Zahniser ${ }^{2}$, and Richard M. Allen ${ }^{1}$ \\ ${ }^{1}$ University of Colorado Denver, Department of Psychology \\ ${ }^{2}$ University of Colorado Denver, Department of Pharmacology and Neuroscience Program
}

\begin{abstract}
Rationale-We have previously described a model in which adult outbred male Sprague-Dawley rats are classified as either low or high cocaine responders (LCRs or HCRs, respectively) based on acute cocaine-induced open-field activation. This model revealed important individual differences in cocaine's effects, including that LCRs exhibited greater responding than HCRs on a progressive-ratio schedule of cocaine reinforcement. However, no LCR/HCR differences in acquisition of cocaine self-administration $(0.25 \mathrm{mg} / \mathrm{kg} / 12 \mathrm{~s}$ infusion) were observed under these conditions.
\end{abstract}

Objectives-To determine if LCRs and HCRs differ in the effectiveness of cocaine to function as a reinforcer under a broader range of conditions, the present study assessed the acquisition of cocaine self-administration (fixed ratio 1 schedule of reinforcement) as a function of i.v. cocaine dose $(0.1875,0.375,0.5,1$, or $1.5 \mathrm{mg} / \mathrm{kg} / 6 \mathrm{~s}$ infusion $)$.

Results-LCRs and HCRs did not differ significantly on any measure of acquisition examined, including day to meet acquisition criterion, percent acquired, and cocaine intake. The effect of dose on percent acquired and rate of acquisition peaked at the $1 \mathrm{mg} / \mathrm{kg} / \mathrm{infusion}$ dose of cocaine. In contrast, the effect of dose on cocaine intake was linear, with the highest rate of intake occurring at the $1.5 \mathrm{mg} / \mathrm{kg} /$ infusion dose of cocaine.

Conclusions-LCRs and HCRs do not appear to differ in their acquisition of cocaine reinforced operant responding across a range of cocaine doses, including conditions that lead to high levels of cocaine intake.

\section{Introduction}

Cocaine abuse and addiction remain significant public health problems; and despite great effort, effective pharmacological treatments are still unavailable. One contributing factor to this issue may be the large degree of variability that is seen in the response of individuals to cocaine. For example, it is estimated that $10-15 \%$ of all initial intranasal cocaine users will progress to addiction (Gawin 1991). Further, individual differences in the initial subjective effects of cocaine have been found to predict long-term cocaine use and dependence (Lambert et al. 2006).

Similar to humans, individual differences in the effects of cocaine are also seen in rats. There are now many models of individual differences that distinguish animals based on unique characteristic behaviors including: response to novelty (i.e., low or high novelty 
responders, LRs or HRs, respectively; Piazza et al. 1989), self-grooming behavior (Homberg et al. 2002), avoidance behavior (Corda et al. 2005), impulsivity (Belin et al. 2008) and response to methamphetamine (Kamens et al. 2005). These behavioral phenotypes are often found to differ in some aspect of the rewarding and reinforcing effects of cocaine. For example, HRs have been found to exhibit enhanced acquisition of low doses of cocaine relative to LRs (Mantsch et al. 2001; Piazza et al. 2000). Findings like this are important given that the ability of cocaine to function as a reinforcer is a primary determinant of abuse potential.

Our lab has worked with a model that distinguishes outbred male Sprague-Dawley rats based on drug response, specifically the magnitude of their locomotor response to an acute injection of cocaine $(10 \mathrm{mg} / \mathrm{kg}$, i.p.). Similar to other models of individual differences (Mantsch et al. 2001; Piazza et al. 1989; Piazza et al. 2000), this model uses a simple median split to classify the wide distribution of responses into two groups. Following single exposure to this dose of cocaine, the distribution of cocaine-induced locomotor activity scores was unimodal, however, it was flatter than a normal distribution when compared to the distribution of saline-induced locomotor activity scores in the same animals (Sabeti et al. 2002). This formed the basis for classification of rats with cocaine-induced locomotor activity below the median as low cocaine responders (LCRs), and rats above the median as high cocaine responders (HCRs).

The large degree of variability in initial cocaine-induced locomotor activity results, at least in part, from differences in the ability of cocaine to inhibit function of the striatal dopamine transporter (DAT). Using this classification based on the median split, cocaine's inhibition of the DAT was greater in HCRs than LCRs following acute experimenter administered cocaine (Sabeti et al. 2002). However, following repeated experimenter administered cocaine, cocaine's inhibition of the DAT increased selectively in LCRs, accompanied by the development of cocaine-induced locomotor sensitization in these animals (Sabeti et al. 2003). Over the past ten years our lab has investigated whether or not this classification predicts other differences in the biochemical and behavioral effects of cocaine and has found a number of important differences between LCRs and HCRs.

Based on previous findings in LCRs and HCRs (e.g., locomotor sensitization and conditioned place preference, LCRs > HCRs; Allen et al. 2007; Sabeti et al. 2003), we predicted that LCRs would more rapidly acquire low-dose cocaine $(0.25 \mathrm{mg} / \mathrm{kg}$ delivered over 12-sec) self-administration than HCRs. However, despite LCR/HCR differences in breakpoints on a progressive-ratio (PR) schedule of cocaine reinforcement (LCRs > HCRs), no LCR/HCR differences were observed in acquisition (Mandt et al. 2008). Importantly, in that study, LCRs and HCRs were tested for acquisition of self-administration reinforced by a single dose of cocaine. Thus, given the potential importance of individual differences for cocaine addiction behaviors, the present study thoroughly assessed the reinforcing effectiveness of cocaine in rats classified as LCRs and HCRs, by determining the ability of a broad range of self-administered doses of cocaine $(0.1875-1.5 \mathrm{mg} / \mathrm{kg} /$ infusion delivered over $6 \mathrm{sec}$ ) to reinforce the acquisition of operant responding.

\section{Materials and Methods}

\section{Animals}

Five separate groups of outbred male Sprague-Dawley rats $(N=136 ; 0.1875 \mathrm{mg} / \mathrm{kg}, n=28$; $0.375 \mathrm{mg} / \mathrm{kg}$ group, $n=32 ; 0.5 \mathrm{mg} / \mathrm{kg}$ group, $n=22 ; 1 \mathrm{mg} / \mathrm{kg}$ group, $n=24 ; 1.5 \mathrm{mg} / \mathrm{kg}$ group, $n=30)$ weighing between $225-250 \mathrm{~g}(\sim 8$ weeks of age) were purchased from Charles River Laboratories (Wilmington, MA) and used in this study. Each dose was tested as a separate experiment. All rats were housed individually with ad libitum access to food 
and water in an animal care facility at the University of Colorado Denver - Downtown Campus (UCD). To remain consistent with all previous LCR/HCR studies, rats were housed on a 12-h light/dark cycle (lights on at $0600 \mathrm{~h}$ ), and all testing was conducted during the light cycle. All animal care and use procedures were in strict accordance with the NIH Guide for the Care and Use of Laboratory Animals and were approved by the UCD Institutional Animal Care and Use Committee.

\section{Catheter construction and placement}

Intravenous catheters were constructed in the laboratory and surgically implanted into the right jugular vein under ketamine $(100 \mathrm{mg} / \mathrm{kg}$, i.m. ) and xylazine $(10 \mathrm{mg} / \mathrm{kg}$, i.m. $)$ anesthesia using established procedures (Caine et al. 1993; Thomsen and Caine 2005). Rats received acetaminophen as an analgesic in their drinking water $(20 \mathrm{mg} / \mathrm{ml})$ for $48 \mathrm{~h}$ pre- and postsurgery. Rats recovered from surgery for at least 1 week before self-administration training began. Catheters were flushed with $0.3 \mathrm{ml}$ of bacteriostatic $0.9 \%$ sodium chloride containing heparin (30 Units/ml) both before and after each self-administration session. Sodium thiopental $(20 \mathrm{mg} / \mathrm{kg}$, i.v.) was administered at the conclusion of the experiment to verify catheter patency.

\section{Locomotor activity}

Locomotor activity testing was conducted as previously described (Mandt and Zahniser 2010). Briefly, rats were taken to the behavioral testing room in their home cage and allowed to habituate for $45-60 \mathrm{~min}$. At the start of the behavioral recording session, rats were placed in open field activity chambers consisting of Plexiglas boxes $(43.2 \times 43.2 \mathrm{~cm})$ fitted with a photobeam frame (16 beams per dimension; Med Associates, St. Albans, VT, USA). After acclimation to the novel environment for $90 \mathrm{~min}$, rats were injected with cocaine $(10 \mathrm{mg} / \mathrm{kg}$, i.p.) and returned to the chamber for $30 \mathrm{~min}$. Locomotor activity was quantified using the automated consecutive horizontal photobeam interruptions converted to distance traveled $(\mathrm{cm})$ per 10-min bin. The sum of distance traveled over the 30 min postcocaine was used to determine the median split for all rats within each group, which was then used to categorize rats as either LCRs or HCRs. A more detailed analysis of behavioral differences between LCRs/HCRs over a longer post-cocaine time-course has been presented elsewhere (Gulley et al. 2003; Mandt and Zahniser 2010; Sabeti et al. 2002).

\section{Self-administration training}

Rats self-administered cocaine during the light cycle in 16 Plexiglas and metal operant conditioning chambers $(29 \times 24 \times 21 \mathrm{~cm}$; Med Associates $)$ that were housed within soundattenuating cabinets. The chambers had two retractable levers on the front wall with stimulus lights positioned $6 \mathrm{~cm}$ above each lever. A tone presentation speaker (Sonalert Tone Generator, $2900 \mathrm{~Hz}$ ) and a white noise speaker $(90 \mathrm{~dB})$ were mounted $12 \mathrm{~cm}$ above the floor on the wall opposite the levers. A houselight $(100 \mathrm{~mA})$ was mounted $6 \mathrm{~cm}$ above the tone speaker, and a computer-controlled syringe pump delivered cocaine infusions. All behavioral events were monitored and controlled by a personal computer using MED-PC for Windows software (Med Associates).

All self-administration sessions began with the extension of the retractable levers, white noise activation, and illumination of the stimulus light on the right side of the chamber. One sec after session initiation, a cocaine priming infusion was delivered $(0.1875,0.375,0.5,1$ or $1.5 \mathrm{mg} / \mathrm{kg} / \mathrm{inf}$ in a volume of $0.2 \mathrm{ml}$ over $5-7 \mathrm{sec}$, based on the weight of the rat). During this priming infusion and during all subsequent self-administered infusions, the stimulus light over the active lever was turned off, and a tone-houselight stimulus complex was activated for $15 \mathrm{sec}$ coinciding with a "time out" period. 
Acquisition of cocaine self-administration was measured in $2 \mathrm{~h}$ sessions over 14 days, and testing was conducted five days a week. Responses on the right lever were reinforced with a cocaine infusion $(0.1875,0.375,0.5,1$ or $1.5 \mathrm{mg} / \mathrm{kg}$ ) according to a fixed ratio one (FR1) schedule of reinforcement. The doses in this range are spaced at irregular intervals to accommodate a transition in laboratory methods (i.e., to future studies generating doseresponse curves with $0.1875,0.375,0.75$, and $1.5 \mathrm{mg} / \mathrm{kg} /$ infusion doses of cocaine). Responses emitted on the right lever during cocaine infusion and stimulus complex presentation were not reinforced and were recorded separately from reinforced responses. Responses on the left lever were recorded but had no programmed consequence. To remain consistent with our previously published analysis of acquisition in LCRs and HCRs, acquisition in these experiments was defined as the first of three consecutive sessions during which a rat consumed at least $5 \mathrm{mg} / \mathrm{kg}$ cocaine (Mandt et al. 2008). In our lab, rats that meet this criterion continue to reliably self-administer cocaine; and these criteria are similar to intake-based acquisition criterion used by other labs (e.g., Carroll and Lac 1997; Mantsch et al. 2001).

\section{Exclusions and exceptions}

In total, 17 of the 136 rats used in the dose-response study were excluded from all final data analyses. Three rats (2 HCRs and 1 LCR) from the $0.1875 \mathrm{mg} / \mathrm{kg}$ group, four rats (2 LCRs and 2 HCRs) from the $0.375 \mathrm{mg} / \mathrm{kg}$ group, four rats (2 LCRs and 2 HCRs) from the $0.5 \mathrm{mg} /$ $\mathrm{kg}$ group, 2 rats (1 LCR and $1 \mathrm{HCR}$ ) from the $1 \mathrm{mg} / \mathrm{kg}$ group, and three rats (1 LCR and 2 HCRs) from the $1.5 \mathrm{mg} / \mathrm{kg}$ group had catheter patency failure before meeting acquisition criteria. One rat from the $0.375 \mathrm{mg} / \mathrm{kg}$ group died during the experiment before a complete data set was collected and, thus, was also excluded from final analysis.

In addition, 1 rat (LCR) in the $0.5 \mathrm{mg} / \mathrm{kg}$ group was excluded from intake analysis, but was included in percent acquisition analysis. This rat acquired self-administration in session 2 but had catheter patency failure in session 12. Thus, the nominal level measure of acquisition (yes/no) was met, but the ratio level measure of intake over 14-sessions was not.

\section{Data analysis}

Statistical analyses were conducted using PASW Statistics, version 18.0 (IBM Corp., Somers, NY, USA) and Prism 5 for Mac OS X, version 5.0c (GraphPad Software Inc., La Jolla, CA, USA). Locomotor activity score (distance traveled in $\mathrm{cm}$ ) represents horizontal movement throughout the open field apparatus. Other measures, such as rearing, stereotypy, and time spent along the periphery were not analyzed in this study. Cocaine intake over the 14-session experiment was analyzed with three-way repeated measures ANOVA (RMANOVA; PASW). Classification, dose, and session were treated as independent variables; and intake was treated as the dependent measure. Cocaine intake pre- and postacquisition day was analyzed with three-way RMANOVA. Only the first four acquisition sessions (i.e., $X$ to $X+3$ ) were analyzed because this was the furthest point at which all rats had complete data. It should be noted that only intake data from rats acquiring selfadministration were analyzed, resulting in additional excluded data as a function of cocaine dose (e.g., $13 / 27$ rats acquired at $0.375 \mathrm{mg} / \mathrm{kg}$ vs. $19 / 22$ rats acquired at $1 \mathrm{mg} / \mathrm{kg}$; see Results). Further, rats in the $0.1875 \mathrm{mg} / \mathrm{kg} / \mathrm{inf}$ group were not included in either intake analysis because only 2 of 25 rats met acquisition criterion within 14 sessions, resulting in data that could only be expressed as mean values \pm range, rather than mean values \pm SEM as with each of the other dose groups. When main or interaction effects were revealed, oneway ANOVA or RMANOVA were used for post-hoc analyses. When the assumption of sphericity was violated for a particular repeated-measures analysis, as revealed by Mauchly's test statistic, tests of significance were based on the more conservative Huynh- 
Feldt-corrected degrees of freedom. The symbol, ${ }^{\text {a }}$, indicates Huynh-Feldt-corrected values throughout the text.

Acquisition percentage over the 14-session experiment was analyzed using Kaplan-Meier survival analysis and Chi square analysis (Prism). Differences in acquisition percentage between LCRs and HCRs for each individual dose and dose comparisons within LCRs and HCRs were determined using the Gehan-Breslow-Wilcoxon Test with pairwise comparisons corrected for multiple comparisons using the Bonferrroni method (Prism).

\section{Drugs}

The National Institute on Drug Abuse generously provided the (-)cocaine hydrochloride used in these studies. For i.p. injections, cocaine was dissolved in sterile saline $(0.9 \%$ sodium chloride) at a concentration of $10 \mathrm{mg} / \mathrm{ml}$ and administered in a volume of $1 \mathrm{ml} / \mathrm{kg}$. For i.v. infusions, cocaine was dissolved in sterile saline containing 1.7 USP Units $/ \mathrm{ml}$ heparin. To check catheter patency, sodium thiopental (Sigma-Aldrich, St. Louis, MO, USA) was dissolved in saline and administered i.v. at $20 \mathrm{mg} / \mathrm{kg}$. Drug weights refer to the salt.

\section{Results}

\section{Analysis of cocaine intake as a function of session or day of acquisition}

Analysis of daily cocaine intake over the 14-session experiment in the rats that acquired self-administration of the various doses of cocaine $(0.375-1.5 \mathrm{mg} / \mathrm{kg} / \mathrm{inf}$; Fig. $1 \mathrm{~A})$ revealed a significant session $\times$ dose interaction $\left[F(39,611)=2.4^{\mathrm{a}}, p=0.001\right]$, but neither LCR/HCR classification $\times$ session $\left[F(13,611)=1.2^{\mathrm{a}}, p=0.284\right]$ nor classification $\times$ dose $\times$ session $\left[F(39,611)=0.9^{\mathrm{a}}, p=0.463\right]$ interactions. It should be noted that animals that did not acquire self-administration were excluded from intake analysis because their behavior was qualitatively different than rats that acquired the operant (i.e., they did not consume cocaine). Subsequent post-hoc analyses of cocaine intake in the different dose groups on each of the 14 sessions revealed significant differences in intake (Fig 1A). Rats selfadministering $1.5 \mathrm{mg} / \mathrm{kg}$ cocaine consumed significantly more cocaine than: rats in all other dose groups on the first and last session of the experiment; rats in the $0.375 \mathrm{mg} / \mathrm{kg}$ group on sessions 11, 12 and 13; and rats in the $1 \mathrm{mg} / \mathrm{kg}$ group on session 12. Although there were some other significant between group differences at the latter sessions, there were no significant between group differences in intake on sessions $2-10$.

One issue with the previous analysis is that it conflates effects of the number of rats that acquired the operant at any given session with individual changes in cocaine intake postacquisition. Thus, Fig 1B depicts cocaine intake in the rats aligned according to our predefined acquisition day (the first of 3 consecutive days of at least $5 \mathrm{mg} / \mathrm{kg}$ cocaine consumption; see Methods). Analysis of cocaine intake on the session prior to the first day of acquisition criterion and the first four sessions post-acquisition $(X$ to $X+3)$ revealed a significant session $\times$ dose interaction $\left[F(12,148)=3.6^{\mathrm{a}}, p<0.001\right]$, but neither LCR/HCR classification $\times$ session $\left[F(4,148)=0.8^{\mathrm{a}}, p=0.513\right]$ nor classification $\times$ dose $\times$ session $\left[F(12,148)=0.7^{\mathrm{a}}, p=0.721\right]$ interactions. It should be noted that rats without $\mathrm{X}-1$ were dropped by the repeated measures analysis. However, intake was indistinguishable between the 9 rats in the $1 \mathrm{mg} / \mathrm{kg}$ group that were excluded and the 10 rats that were included in the analysis $[F(3,51)=1.9, p=0.128]$, and for the 5 rats in the $1.5 \mathrm{mg} / \mathrm{kg}$ group that were excluded and the 13 rats that were included in the analysis $\left[F(3,48)=0.49^{\mathrm{a}}, p=0.651\right]$. Subsequent post-hoc analysis of cocaine intake in the different dose groups on each of these sessions revealed significant differences in cocaine intake (Fig 1B). Cocaine intake did not differ significantly between the groups on the session prior to acquisition or on the first day 
acquisition criterion was met. However, rats self-administering $1.5 \mathrm{mg} / \mathrm{kg}$ cocaine consumed significantly more cocaine than rats in the 0.375 and $1 \mathrm{mg} / \mathrm{kg}$ groups on each of the next two sessions and all rats by the fourth post-acquisition session. There were no significant LCR/ HCR differences in cocaine intake using either form of analysis (see Table 1).

\section{Lever responding as a function of acquisition day}

Acquisition in these experiments was defined according to intake criterion, which resulted in different levels of response requirements depending on cocaine dose. Thus, to address the possibility that the low response requirement for the higher cocaine doses (i.e., 1 and 1.5 $\mathrm{mg} / \mathrm{kg}$ cocaine) might not truly represent acquisition of the operant, active and inactive lever responding as a function of acquisition session are presented in Fig 2. Active and inactive lever responding for the three sessions pre- and first seven sessions post-acquisition criterion are presented for rats self-administering 0.375 (Fig 2A), 0.5 (Fig 2B), 1 (Fig 2C) or 1.5 (Fig 2D) $\mathrm{mg} / \mathrm{kg}$ cocaine. Similar to intake, responses in the $0.1875 \mathrm{mg} / \mathrm{kg}$ group are not presented because only 2 of 25 animals acquired self-administration within the 14-session experiment. For each of the dose groups, active to inactive lever discrimination did not differ over the first three sessions prior to meeting acquisition criterion (Fig 2). In contrast, by the third criterion session, each group of rats exhibited a greater than 3:1 ratio of active to inactive lever responding (Fig 2). Similar to intake analyses, there were no significant differences in lever responding between LCRs and HCRs (data not shown).

\section{Cocaine dose effects on rate of acquisition and acquisition percentage}

The overall percentages of rats reaching acquisition criterion in each of the different dose groups are presented for each of the sessions as an inverse survival function (Fig 3A). Survival analysis indicated that dose was a significant factor on acquisition $\left(\chi^{2}=35.2, d f=\right.$ $4, p<0.001$ ). The median times to reach $50 \%$ acquisition were $>14,>14,7.5,3.5$ and 8 days for the $0.1875,0.375,0.5,1$ and $1.5 \mathrm{mg} / \mathrm{kg}$ cocaine groups, respectively. By session $14,8 \%$ $(2 / 25)$ of rats in the $0.1875 \mathrm{mg} / \mathrm{kg}$ group, $48 \%$ (13/27) of rats in the $0.375 \mathrm{mg} / \mathrm{kg}$ group, $61 \%$ $(11 / 18)$ of rats in the $0.5 \mathrm{mg} / \mathrm{kg}$ group, $86 \%(19 / 22)$ of rats in the $1 \mathrm{mg} / \mathrm{kg}$ group, and $67 \%$ $(18 / 27)$ of rats in the $1.5 \mathrm{mg} / \mathrm{kg}$ group acquired self-administration behavior. Chi square analysis of the total number of rats reaching acquisition criterion by session 14 revealed a significant effect of dose $\left(\chi^{2}=32.7, d f=4, p<0.001\right)$, with more rats acquiring at the higher doses.

There were no significant differences between LCRs and HCRs in rate or overall percent acquisition at any dose (see Table 1). However, dose effects within LCRs or HCRs were not identical. Survival analysis revealed that dose was a significant factor on acquisition of selfadministration behavior in LCRs $\left(\chi^{2}=23.0, d f=4, p<0.001\right.$; Fig 3B) and HCRs $\left(\chi^{2}=14.4\right.$, $d f=4, p=0.006$; Fig 3C). Median times to reach 50\% acquisition for LCRs were $>14,>14$, 9,1 and 11 days for the $0.1875,0.375,0.5,1$ and $1.5 \mathrm{mg} / \mathrm{kg}$ cocaine groups, respectively. Bonferroni-corrected pairwise comparisons (corrected $p$ value $=0.012$ ) revealed that LCRs exhibited significantly enhanced acquisition of $1 \mathrm{mg} / \mathrm{kg}$ cocaine self-administration relative to $0.1875 \mathrm{mg} / \mathrm{kg}\left(\chi^{2}=15.8, d f=1, p<0.001\right), 0.375 \mathrm{mg} / \mathrm{kg}$ cocaine $\left(\chi^{2}=7.1, d f=1, p=\right.$ $0.007)$ and $1.5 \mathrm{mg} / \mathrm{kg}$ cocaine $\left(\chi^{2}=7.6, d f=1, p=0.005\right)$, but not $0.5 \mathrm{mg} / \mathrm{kg}$ cocaine $(p=$ 0.12). Median times to reach $50 \%$ acquisition for HCRs were $>14,10,7,5$ and 6 days for the $0.1875,0.375,0.5,1$ and $1.5 \mathrm{mg} / \mathrm{kg}$ cocaine groups, respectively. Bonferroni-corrected pairwise comparisons (corrected $p$ value $=0.012$ ) revealed that HCRs exhibited significantly enhanced acquisition of $1 \mathrm{mg} / \mathrm{kg}$ cocaine self-administration relative to $0.1875 \mathrm{mg} / \mathrm{kg}\left(\chi^{2}=\right.$ $19.0, d f=1, p<0.001)$, but none of the other doses $(0.375 \mathrm{mg} / \mathrm{kg}, p=0.06 ; 0.5 \mathrm{mg} / \mathrm{kg}, p=$ $0.17 ; 1.5 \mathrm{mg} / \mathrm{kg}, p=0.15$ ). 


\section{Discussion}

In this study we completed a more thorough assessment of the reinforcing effectiveness of cocaine in rats classified as LCRs or HCRs, by analyzing acquisition of cocaine selfadministration as a function of i.v. cocaine dose. While this study did not reveal significant differences in the acquisition of cocaine self-administration between LCRs and HCRs, it did reveal an effect of cocaine dose that is masked in traditional forms of data analysis and presentation. Aligning cocaine intake on the day acquisition criteria are met, rather than from the start of the experiment, revealed that very early on in training rats selfadministering $1.5 \mathrm{mg} / \mathrm{kg}$ cocaine consumed significantly more cocaine than rats selfadministering the lower doses. This effect is lost when intake is analyzed according to session number, because changes in rate of intake in individual animals are conflated with individual differences in rate of learning.

Consistent with our previous report in which no significant differences were revealed between LCRs and HCRs in rate of acquisition or percentage of rats that acquired selfadministration reinforced by $0.25 \mathrm{mg} / \mathrm{kg}$ cocaine over $12 \mathrm{sec}$ (Mandt et al. 2008), here also no significant differences were observed between LCRs and HCRs in acquisition of selfadministration reinforced by a broad range of cocaine doses $(0.1875-1.5 \mathrm{mg} / \mathrm{kg}$ over $6 \mathrm{sec})$ over the course of 14 sessions. However, the ability of cocaine to function as a reinforcer within LCRs or HCRs was not identical. This is highlighted by the finding that $1 \mathrm{mg} / \mathrm{kg}$ cocaine was the single most effective dose for acquisition for LCRs, whereas many doses were similarly effective for HCRs (see Results and Table 1). LCRs acquisition of selfadministration reinforced by this dose of cocaine occurred significantly faster than for all other doses except $0.5 \mathrm{mg} / \mathrm{kg}$, whereas HCRs only exhibited enhanced acquisition of $1 \mathrm{mg} /$ $\mathrm{kg}$ relative to $0.1875 \mathrm{mg} / \mathrm{kg}$ cocaine.

We were intrigued that $1 \mathrm{mg} / \mathrm{kg}$ cocaine stood out from the other doses for LCRs. LCR/ HCR differences in the acute and repeated effects of cocaine were first defined using $10 \mathrm{mg} /$ kg i.p. cocaine (Sabeti et al. 2002; 2003). In cocaine naïve animals this dose has been shown to produce similar brain cocaine levels and acute increases in locomotor activity as $1 \mathrm{mg} / \mathrm{kg}$ i.v. cocaine (Allen et al. 2007; Orona et al. 1994). Repeated experimenter administered exposure to both $10 \mathrm{mg} / \mathrm{kg}$ i.p. and $1 \mathrm{mg} / \mathrm{kg}$ i.v. cocaine results in locomotor sensitization selectively in LCRs, and repeated experimenter administered $1 \mathrm{mg} / \mathrm{kg}$ i.v. cocaine leads to greater CPP in LCRs than HCRs (Allen et al. 2007; Mandt et al. 2008; Sabeti et al. 2003). However, despite enhanced effectiveness relative to the other doses for LCRs, LCRs and HCRs did not differ in self-administration of this dose. It is possible that cocaine-elicited changes (e.g., locomotor sensitization) that result from these experimenter delivered administrations are different from the changes induced by self-administration of this same dose. In fact, non-contingent and contingent cocaine are known to produce differential effects on systems involved in sensitization (Chen et al. 2008; Lecca et al. 2007; Miguens et al. 2008; but see Zapata et al. 2003). Though we are interested to pursue this experimental idea further, the current study suggests that LCR/HCR classification does not robustly impact rates of acquisition of cocaine self-administration across a wide range of doses.

A number of different animal models have been used to study individual differences as predictors of drug reward and reinforced behavior. One of the most widely studied models distinguishes animals based on their habituation response to an inescapable novel environment, using the median split to classify rats as LRs and HRs, respectively (Piazza et al. 1989). Selectively-bred lines of LRs and HRs have also been generated (Stead et al. 2006). Assessment of the sensitivity to the reinforcing effectiveness of cocaine showed that HRs, more readily than LRs, will self-administer low doses of amphetamine and cocaine over 5 - 7 sessions (Piazza et al. 1989; Piazza et al. 2000). However, this difference in 
acquisition sensitivity disappears at moderate to high cocaine doses (Mantsch et al. 2001). Consistent with some, but not all, of these previous findings, individual differences in novelty-induced locomotor activity were not found to predict any of the self-administration measures tested in this study (e.g., percent acquisition, intake, etc.) using mostly higher doses of cocaine (data not shown).

A recent study simultaneously assessing a number of individual differences including novelty and cocaine-induced locomotor activity, concluded that cocaine-induced locomotor activity was the single best predictor of active lever pressing for $0.8 \mathrm{mg} / \mathrm{kg}$ cocaine (Schramm-Sapyta et al. 2011). It should be noted, however, that this study found a positive correlation between cocaine-induced locomotor activity and active lever pressing, suggesting that an initial high cocaine-induced locomotor response was predictive of greater activity on this measure. Conversely, we have generally found greater effects in animals with low initial cocaine-induced activity (i.e., LCRs), on measures of repeated cocaineinduced behaviors (e.g., locomotor sensitization and CPP). Further, this finding is in contrast to our previous and current results, which did not reveal significant differences between LCRs/HCRs during self-administration on a FR1 schedule of reinforcement. However, there are substantial differences between the Schramm-Sapyta study and our current study that make direct comparison difficult. For example, animals were pre-trained to respond for food, unlike our animals, which received no operant training prior to cocaine selfadministration. In addition, cocaine-induced locomotor activity in that study was based on the first 60-min of post-cocaine activity, whereas we have always defined LCRs/HCRs based on the first 30-min of cocaine-induced locomotor activity. Regardless, this finding still suggests that individual differences in cocaine-induced locomotor activity are an important variable for further study.

To our knowledge, analysis of dose-dependent cocaine intake from the day of acquisition has not previously been presented in the literature. The day of acquisition has been used as a measure for determining the percentage of animals that acquire the operant as a function of session (e.g., Carroll and Lac 1997), but acquisition day has not been applied for intake analysis. Rather, intake or lever responding has been presented as a function of session in the entire group of animals that ultimately acquired the operant. These studies have provided extremely valuable information about the effects of cocaine dose on self-administration behavior. However, this type of analysis conflates animals learning to self-administer cocaine with changes in intake in animals that have already acquired the behavior. To separate these acquisition parameters, we aligned cocaine-intake in the different dose groups according to our pre-defined acquisition day. This analysis revealed that, whereas there were no differences in cocaine intake on the day before or on the first day our criteria was met, rats self-administering $1.5 \mathrm{mg} / \mathrm{kg}$ cocaine thereafter consumed significantly more cocaine than all other doses (Fig 1B). This is in contrast to intake analysis as a function of session, which did not reveal significantly greater intake in the $1.5 \mathrm{mg} / \mathrm{kg}$ group until the final days of the experiment (i.e., sessions 12, 13 and 14; Fig 1A).

This study also replicated previous findings regarding the effects of cocaine dose, which have found that increasing the dose of self-administered cocaine increases both the rate of acquisition and overall percentage of animals that acquire the operant (Carroll and Lac 1997; Schenk et al. 1993). Increasing the dose of self-administered cocaine from $0.1875-1 \mathrm{mg} / \mathrm{kg}$ decreased latency to acquisition and increased the overall percentage of animals acquiring. A further increase in dose to $1.5 \mathrm{mg} / \mathrm{kg}$ cocaine increased latency and decreased overall percentage to levels similar to $0.5 \mathrm{mg} / \mathrm{kg}$ cocaine, suggesting $1.5 \mathrm{mg} / \mathrm{kg}$ may be on the descending limb of the cocaine dose response curve for acquisition. One important consideration for conclusions about acquisition parameters is how acquisition is defined. Our lab uses an intake criterion that necessitates a different response requirement as a 
function of dose: high response requirements at low doses and low response requirements at high doses. This raises the possibility that acquisition of self-administration at the higher unit doses of cocaine ( 1 and $1.5 \mathrm{mg} / \mathrm{kg}$ ) might not truly represent acquisition of the operant, as animals only have to make 5 and 4 responses, respectively, to meet criterion. However, analysis of lever discrimination for all the doses where acquisition occurred within the 14day period revealed clear lever discrimination (greater than 3:1 ratio of active to inactive lever responding; Fig 2), even at the highest dose when response requirements were the lowest.

The present study employed a more complete dose-response analysis of the ability of cocaine to reinforce operant responding in rats classified as LCRs and HCRs. Consistent with our previous report (Mandt et al. 2008), individual differences in acute cocaine-induced locomotor activity (i.e., LCRs and HCRs) do not appear to be a reliable predictor of acquisition of cocaine self-administration. However, this study replicated previous findings about the effect of cocaine dose on acquisition of operant responding and extended these findings to include a novel method of intake analysis. This analysis revealed an effect of higher dose cocaine that is masked by more common forms of analysis and provides important information about the effect of cocaine dose during the earliest stages of selfadministration behavior.

\section{Acknowledgments}

This work and the authors were supported by NIH Grants R01 DA004216 and K05 DA015050. We would like to thank Emily Gomez, Jillian Laggart, Kari Massar, Merissa Pickell, and Alyssa Schickedanz for their dedicated help with data collection. The authors have no conflict of interest to disclose.

\section{References}

Allen RM, Everett CV, Nelson AM, Gulley JM, Zahniser NR. Low and high locomotor responsiveness to cocaine predicts intravenous cocaine conditioned place preference in male Sprague-Dawley rats. Pharmacol Biochem Behav. 2007; 86:37-44. [PubMed: 17250883]

Belin D, Mar AC, Dalley JW, Robbins TW, Everitt BJ. High impulsivity predicts the switch to compulsive cocaine-taking. Science. 2008; 320:1352-5. [PubMed: 18535246]

Caine, SB.; Lintz, R.; Koob, GF. Intravenous drug self-administration techniques in animals. In: Sahgal, A., editor. Behavioral neuroscience: a practical approach. Oxford UP; Oxford, UK: 1993. p. 117-143.

Carroll ME, Lac ST. Acquisition of i.v. amphetamine and cocaine self-administration in rats as a function of dose. Psychopharmacology (Berl). 1997; 129:206-14. [PubMed: 9084058]

Chen BT, Bowers MS, Martin M, Hopf FW, Guillory AM, Carelli RM, Chou JK, Bonci A. Cocaine but not natural reward self-administration nor passive cocaine infusion produces persistent LTP in the VTA. Neuron. 2008; 59:288-97. [PubMed: 18667156]

Corda MG, Piras G, Lecca D, Fernandez-Teruel A, Driscoll P, Giorgi O. The psychogenetically selected Roman rat lines differ in the susceptibility to develop amphetamine sensitization. Behav Brain Res. 2005; 157:147-56. [PubMed: 15617781]

Gawin FH. Cocaine addiction: psychology and neurophysiology. Science. 1991; 251:1580-6. [PubMed: 2011738]

Gulley JM, Hoover BR, Larson GA, Zahniser NR. Individual differences in cocaine-induced locomotor activity in rats: behavioral characteristics, cocaine pharmacokinetics, and the dopamine transporter. Neuropsychopharmacology. 2003; 28:2089-101. [PubMed: 12902997]

Homberg JR, van den Akker M, Raaso HS, Wardeh G, Binnekade R, Schoffelmeer AN, de Vries TJ. Enhanced motivation to self-administer cocaine is predicted by self-grooming behaviour and relates to dopamine release in the rat medial prefrontal cortex and amygdala. Eur J Neurosci. 2002; 15:1542-50. [PubMed: 12028365] 
Kamens HM, Burkhart-Kasch S, McKinnon CS, Li N, Reed C, Phillips TJ. Sensitivity to psychostimulants in mice bred for high and low stimulation to methamphetamine. Genes Brain Behav. 2005; 4:110-25. [PubMed: 15720407]

Lambert NM, McLeod M, Schenk S. Subjective responses to initial experience with cocaine: an exploration of the incentive-sensitization theory of drug abuse. Addiction. 2006; 101:713-25. [PubMed: 16669905]

Lecca D, Cacciapaglia F, Valentini V, Acquas E, Di Chiara G. Differential neurochemical and behavioral adaptation to cocaine after response contingent and noncontingent exposure in the rat. Psychopharmacology (Berl). 2007; 191:653-67. [PubMed: 16932924]

Mandt BH, Schenk S, Zahniser NR, Allen RM. Individual differences in cocaine-induced locomotor activity in male Sprague-Dawley rats and their acquisition of and motivation to self-administer cocaine. Psychopharmacology (Berl). 2008; 201:195-202. [PubMed: 18685831]

Mandt BH, Zahniser NR. Low and high cocaine locomotor responding male Sprague-Dawley rats differ in rapid cocaine-induced regulation of striatal dopamine transporter function. Neuropharmacology. 2010; 58:605-612. [PubMed: 19951714]

Mantsch JR, Ho A, Schlussman SD, Kreek MJ. Predictable individual differences in the initiation of cocaine self-administration by rats under extended-access conditions are dose-dependent. Psychopharmacology (Berl). 2001; 157:31-9. [PubMed: 11512040]

Miguens M, Crespo JA, Del Olmo N, Higuera-Matas A, Montoya GL, Garcia-Lecumberri C, Ambrosio E. Differential cocaine-induced modulation of glutamate and dopamine transporters after contingent and non-contingent administration. Neuropharmacology. 2008; 55:771-9. [PubMed: 18634806]

Orona RA, Mayfield RD, Cline EJ, Zahniser NR. Repeated intravenous cocaine administration to rats produces behavioral sensitization without changing brain cocaine levels. Neurosci Lett. 1994; 167:121-4. [PubMed: 8177509]

Piazza PV, Deminiere JM, Le Moal M, Simon H. Factors that predict individual vulnerability to amphetamine self-administration. Science. 1989; 245:1511-3. [PubMed: 2781295]

Piazza PV, Deroche-Gamonent V, Rouge-Pont F, Le Moal M. Vertical shifts in self-administration dose-response functions predict a drug-vulnerable phenotype predisposed to addiction. $\mathrm{J}$ Neurosci. 2000; 20:4226-32. [PubMed: 10818158]

Sabeti J, Gerhardt GA, Zahniser NR. Acute cocaine differentially alters accumbens and striatal dopamine clearance in low and high cocaine locomotor responders: behavioral and electrochemical recordings in freely moving rats. J Pharmacol Exp Ther. 2002; 302:1201-11. [PubMed: 12183681]

Sabeti J, Gerhardt GA, Zahniser NR. Individual differences in cocaine-induced locomotor sensitization in low and high cocaine locomotor-responding rats are associated with differential inhibition of dopamine clearance in nucleus accumbens. J Pharmacol Exp Ther. 2003; 305:180-90. [PubMed: 12649367]

Schenk S, Valadez A, McNamara C, House DT, Higley D, Bankson MG, Gibbs S, Horger BA. Development and expression of sensitization to cocaine's reinforcing properties: role of NMDA receptors. Psychopharmacology (Berl). 1993; 111:332-8. [PubMed: 7870971]

Schramm-Sapyta NL, Cauley MC, Stangl DK, Glowacz S, Stepp KA, Levin ED, Kuhn CM. Role of individual and developmental differences in voluntary cocaine intake in rats. Psychopharmacology (Berl). 2011

Stead JD, Clinton S, Neal C, Schneider J, Jama A, Miller S, Vazquez DM, Watson SJ, Akil H. Selective breeding for divergence in novelty-seeking traits: heritability and enrichment in spontaneous anxiety-related behaviors. Behav Genet. 2006; 36:697-712. [PubMed: 16502134]

Thomsen M, Caine SB. Chronic intravenous drug self-administration in rats and mice. Curr Protoc Neurosci. 2005; Chapter 9(Unit 9):20. [PubMed: 18428629]

Zapata A, Chefer VI, Ator R, Shippenberg TS, Rocha BA. Behavioural sensitization and enhanced dopamine response in the nucleus accumbens after intravenous cocaine self-administration in mice. Eur J Neurosci. 2003; 17:590-6. [PubMed: 12581176] 

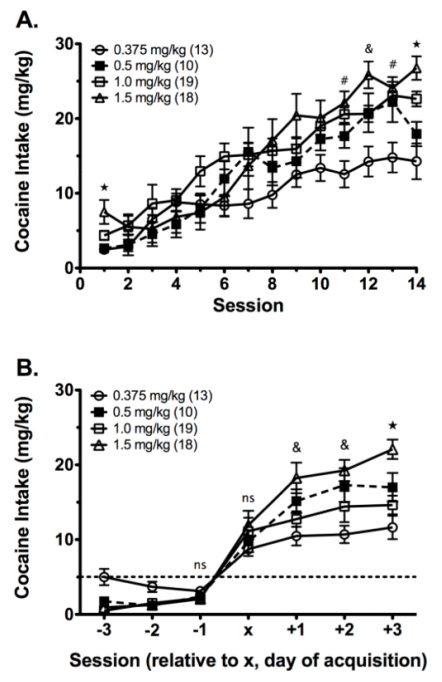

Figure 1.

Cocaine intake as a function of session or acquisition day in each group of rats, regardless of LCR/HCR classification. A Daily cocaine intake over the 14-session experiment is shown for rats self-administering i.v. cocaine $(0.375-1.5 \mathrm{mg} / \mathrm{kg})$ according to a fixed ratio 1 (FR1) schedule of reinforcement. B Cocaine intake is shown for the three sessions prior to and first three sessions post-acquisition in the same groups of rats as in (A). X represents the day of acquisition. $\mathrm{N}$ values are given in parentheses in $(\mathbf{A})$ and $(\mathbf{B})$. Data in $(\mathbf{A})$ and $(\mathbf{B})$ are mean values \pm SEM. $\star p<0.051 .5 \mathrm{mg} / \mathrm{kg}$ vs. all doses; $\boldsymbol{\&} p<0.051 .5 \mathrm{mg} / \mathrm{kg}$ vs. $0.375 \mathrm{mg} / \mathrm{kg}$ and $1.0 \mathrm{mg} / \mathrm{kg}$; \# $p<0.051 .5 \mathrm{mg} / \mathrm{kg}$ vs. $0.375 \mathrm{mg} / \mathrm{kg}$. It should be noted that $\mathrm{N}$ values in (B) represent data for sessions $\mathrm{X}$ to $\mathrm{X}+3$, as not all animals have data from sessions prior to $\mathrm{X}$ (i.e., acquisition occurred on the first session) and thus, $\mathrm{N}$ values are lower for those data points. 

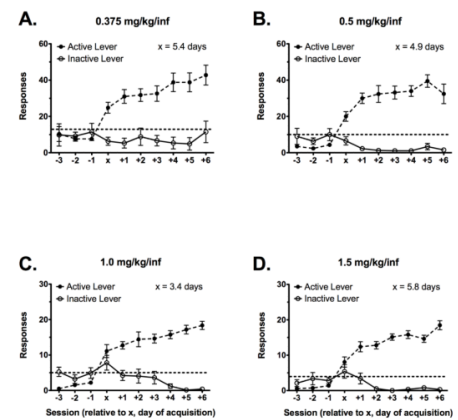

Figure 2.

Active and inactive lever responding as a function of acquisition session in each group of rats, regardless of LCR/HCR classification. Lever responses are shown for the same groups of rats as in Fig. 1B in rats self-administering 0.375 (A), 0.5 (B), 1 (C) or $1.5 \mathrm{mg} / \mathrm{kg}$ (D) cocaine according to an FR1 schedule of reinforcement. X represents the day of acquisition, and average day to acquisition is given in each figure. The dashed horizontal line indicates the corresponding intake criterion for responses. Data are presented as mean values \pm SEM. 
A.

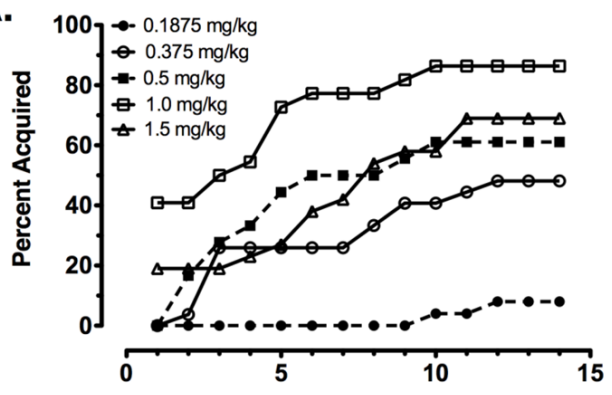

B.

LCRs

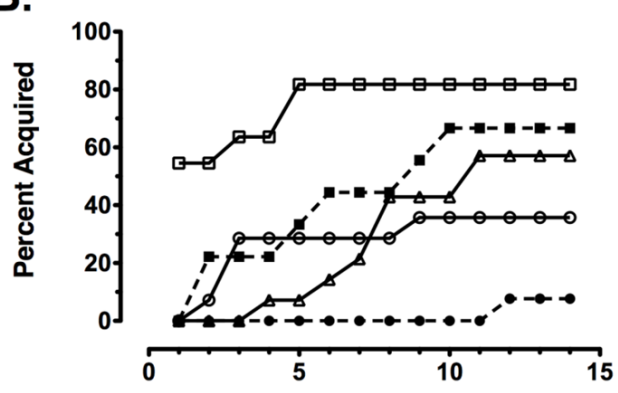

C.

HCRs

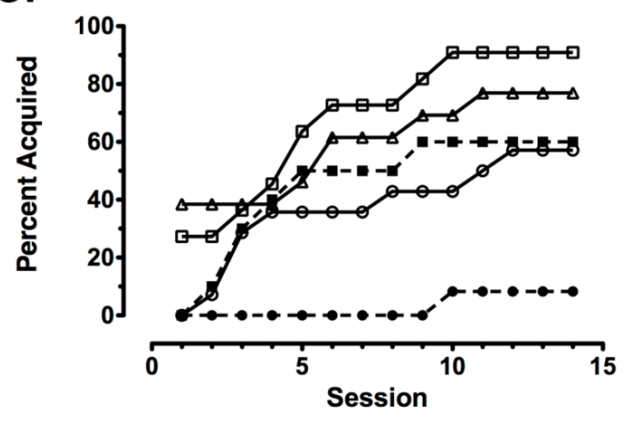

Figure 3.

Acquisition of cocaine self-administration in the entire group of rats tested at each dose and according to LCR/HCR classification. Session-responses for the percentages of rats acquiring cocaine self-administration in the $0.1875(\mathrm{~N}=25), 0.375(\mathrm{~N}=27), 0.5(\mathrm{~N}=18), 1$ $(\mathrm{N}=22)$ and $1.5(\mathrm{~N}=27) \mathrm{mg} / \mathrm{kg}$ groups on each on the 14 daily acquisition sessions for each dose group (A) and for the rats classified as LCRs $(\mathbf{B})$ and HCRs $(\mathbf{C})$ in each dose group. $\mathrm{N}$ values for LCRs/HCRs in the different dose groups are given in Table 1. 


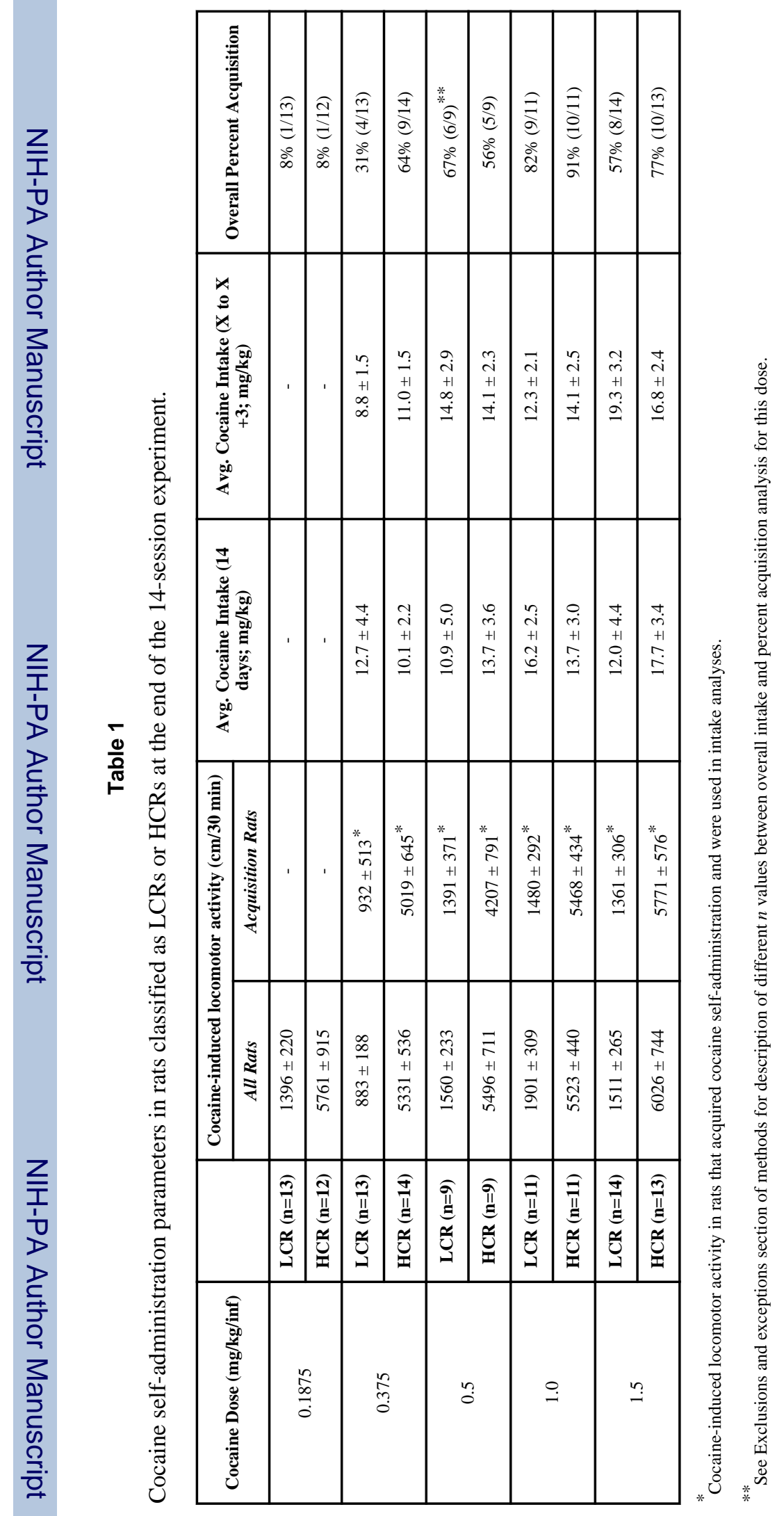

